\title{
DEVELOPMENT OF A BLOOD BANK INFORMATION RETREIVAL SYSTEM USING ANDROID APP
}

\author{
Samson Oloruntoba \\ Department of Computer Science \\ Federal Polytechnic, Ilaro.
}

\author{
John Lekan Akinode \\ Department of Computer Science \\ Federal Polytechnic, Ilaro.
}

Abstract - Blood is the most vital element of human life. It helps to carry the oxygen to the tissues and subsequently takes away $\mathrm{CO}_{2}$ from the tissues through heart and the vascular system. The fundamental responsibility of a blood transfusion service is to provide a sufficient, save and timely supply of blood and blood products. In fulfilling this responsibility, an efficient platform must be designed to provide the synergy between hospitals, blood banks, blood donors and receptors to ensure that the act of blood donation is safe and seamless. Without quick and timely access to donor records, platforms for blood donation, access to blood bank especially in times of emergency becomes very difficult. This paper presents a report on the development of a blood retrieval system to assist in the management of blood donor records and control the distribution of blood in government hospitals. The blood bank information retrieval system provides timely, efficient and confidential and to donor records quick access to medical reports to donors. In this report, we present both a web-based and android based blood donation inventory system that aims at reducing errors in blood transfusion. We have developed a prototype of the system using Cordova and Ionic 2 Technologies for building native mobile application with HTML5, CSS and JavaScript. The proposed system has inbuilt features that permits registered blood banks to send notification to registered blood donors on the application requesting for blood donation.

Keywords: Blood bank, Retrieval system, Web-based, Android app, Inventory

\section{INTRODUCTION}

Human population has skyrocketed over the previous couple of hundred years. The unprecedented growth in the world population has increased the demand for blood supply. Consequently, the population explosion suggests a high number of potential blood donors scattered across the globe. However, despite the exponential growth in population, only $10 \%$ of the World population is involved in blood donation Prathamesh et al., (2016). Maintaining a pool of safe blood and blood products has become a serious concern in several countries. Achieving this aim requires the development and implementation of a national policy and therefore the development of guidelines to control blood transfusion processes (WHO, 2010).

Blood plays a crucial role in regulating the body's systems and maintaining homeostasis. It allows the body to bring essential things such as nutrients and oxygen from central locations (i.e. the lungs or small intestine) to every part of the body. Similarly, blood transports oxygen from the lungs to the cells of the body, where it is needed for metabolism. Therefore, human body cannot live without the blood flowing through it. The human blood provides a platform for transporting nutrients, oxygen and waste products within and outside the cells in the body Kayode et al, (2019).For blood to be in excess and readily available as a result of donation, it has to be collected, stored and preserved for future use, this process is known as blood bank for transfusion Mondal P.K. et al,(2014).Blood Transfusion describe the method of receiving blood into person circulation intravenously through the vein. Transfusions are used for various medical conditions to replace lost components of the blood. Hence, the availability of quality blood in our health centers is essential to the sustenance of human being. However, most hospitals are faced with the challenges of getting adequate blood for patients in time of emergency. At times, the blood banks are unable to locate a donor that matches a particular patient. Hence, there is no synergy between the hospital, blood banks, donor and the receptor. This improper management of blood leads to wastage of available blood and subsequently to loss of live Teena et al., (2014).

Information and Communication Technology (ICT) has played a major role in health care delivery. These include: automation of patient scheduling, web-based hospital management system, disease diagnosis system among others. The inherent problem within the existing manual blood management are often resolved using ICT to provide a seamless and robust platform for connecting the major stakeholders in blood donation supply chain. The infiltration of mobile devices and mobile communication to support a mobile lifestyle makes computing increasingly mobile and ubiquitous today. The growth in numbers and capacity of mobile devices such as mobile phones coupled with widespread availability of inexpensive range of services presents an unprecedented opportunity for mobile health care applications.

In this paper, a web and mobile platform are developed to provide a seamless matching of a potential blood to a patient. The web application serves as a repository for blood banks; the database 663 


\section{International Journal of Engineering Applied Sciences and Technology, 2020}

Vol. 5, Issue 4, ISSN No. 2455-2143, Pages 663-673

Published Online August 2020 in IJEAST (http://www.ijeast.com)

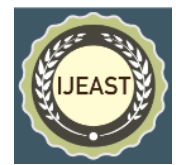

handles the registration and update of blood banks. The mobile app helped to explore the repository for available blood type required from registered blood banks. The web-based application is designed for the blood banks camps, they used web app to control the blood donation inventories and issuance. The android application would be used by blood donors and it has a Google map which will remove the burden of incessant search for the nearest blood donation camp.

\section{THE ANDROID MOBILE PLATFORM}

The Android operating system is built on a modified Linux kernel (see Figure 3). The software stack contains Java applications running on a virtual machine, and system components are written in Java, $\mathrm{C}, \mathrm{C}++$, and XML. Android phones ship with a rich array of built-in activities (the Android term for services), including email, a Web browser, and a map application. The platform embraces a replace-and reuse philosophy, which lets users customize the phone. For example, Android phones come with a built-in photo viewer, which all applications that view photos use. However, users can replace the photo viewer with a customized one, and all applications will automatically call the customized one. All applications use (or reuse) the same activity. This is an example of the system's open design. Margaret B. (2011).

\begin{tabular}{|c|c|c|}
\hline \multicolumn{3}{|c|}{ Applications } \\
\hline \multicolumn{3}{|c|}{ Application Framework } \\
\hline \multirow[b]{2}{*}{$\begin{array}{l}\text { Static } \\
\text { Library }\end{array}$} & \multicolumn{2}{|c|}{ Android Runtime } \\
\hline & \begin{tabular}{|c|} 
Core \\
Runtime \\
Libraries
\end{tabular} & \begin{tabular}{|c|} 
Dalvik \\
Virtual \\
Machine \\
\end{tabular} \\
\hline \multicolumn{3}{|c|}{ Linux Kernel } \\
\hline
\end{tabular}

Figure 1. The android platform

\section{REVIEW OF EXISTING WORK}

This section reviewed some of the existing blood donors and inventory management platforms, and briefly describes their working mechanisms.

Riya Dandekar et al. (2020) proposed a computerized blood bank information system using geofencing with the help of GPS technology to track the blood bank and the requirement of the blood. They deployed geofencing and filtering techniques to help hospitals to match specific blood type with blood receptor.

Kayode et al. (2019) designed a blood bank retrieval system using Android application. The blood bank retrieval system which consists of both web and mobile platform is developed for blood banks system administrators to update the blood inventory system while the mobile app has a search engine to search for blood supplies from the registered blood banks. The system could allow registered blood banks to send a notification to registered blood donors on the application requesting for blood donation.

In Akora B. M.et al. (2018), a Blood Donate Android Mobile Application was developed to improve the blood donation supply chain in Uganda. The mobile app provides a platform for the registration all potential donors and keeps track of their donations with various blood banks. The android application is designed to create a network of blood donors to increase the amount of blood units in stock within Uganda through voluntarism and motivation of blood donors. They integrated an incentive mechanism for donors and stakeholders in the blood donation domain. Hence, donors do not have to solely rely on voluntarism as the main drive for getting more blood donors involved. This is feat is achieved through the integration of loyalty points that will be earned whenever someone donates blood or recommends the application to another party and they are able to download it.

Sadia N. D. (2018) developed an Android based mobile application that can determine the location of a blood donor using GPS location service. The App is also able to find the best matches among the donors available with the help of machine learning algorithms. The algorithms are capable of analyzing the profile of each donor and find the best fit ones with respect to health condition and lifestyle. Furthermore, the app has the capability to determine the exact position of a potential donor on the map. The Blood Donation App will make the easiest and fastest way to get a best match blood donor. Blood Donation Application is user friendly and has the intelligence to find the best matches of blood donors by analyzing the nearby donor's profile. The author used KNN (K-Nearest Neighbor), a machine learning algorithm to match the best donor to the recipient. The aim of this Blood Donation Application is to improve the communication with the people who are in need of blood and the persons who are willing to donate blood in few touches of the Smartphone. This Location based Blood Donation Application will reduce the barrier between blood donors and the people in sever need of blood.

Aishwary Shind et al (2018) in their work, RedDonate, developed a mobile blood bank application that maintains information about donors, monitors blood groups database to assist users in need of blood. Subsequently, this reduces the time spent in searching of blood donors in case of emergency. RedDonate allows user in need to view the details of the donor such as their name, their locality, their cell phone number $\&$ their blood group.

Pradnya Jagtap et al.(2018) presented a cloud based blood donation system using android. The main focus of the research is to develop a software system that will link all donors, control a blood transfusion service and a create a database to hold data on stocks of blood in each area. The software system is divided into three major modules; Android Application (provides interface to donors), Cloud (this handles the database and the server) and the Client Portal. 
Shubham Pande et al (2018) proposed an Android application for managing blood donation. The software system is useful for emergency services, i.e. time of blood Transfusion, Blood Donation etc. It provides a better platform for efficient communication among blood donors and also maintain database of registered donors. The proposed system,E-Blood Bank is an Android application which allows the user to search donors of specific blood group based on their location, in a short period of time. This software helps to display the list of donors and also integrated with GPS for tracking the location of the nearby donors and adopts SMS alerts to disseminate information to donors.

Giridhar Maji et al.(2018) developed an integrated framework for a web based sub systems of a blood management system. They proposed a data warehouse (DW) as an integral part of the integrated framework to store historical blood donation data in a centralized database for analytical processing. The software system would enable the authorities to take informed blood donation camping decision based on the analytical reports from the DW for some area for a particular time and citizen demography. They introduced new measure of humanity (scoring system for good deeds) of citizens called Philanthropy Score (PS) and Philanthropy League (PL) derived from PS.

Abu Naser et al (2016) developed an application for tracking Blood Donors called Mobile Blood Donor Tracker. The mobile application helps to connect patients with the Blood centers, provide seamless blood collections during emergencies and also facilitate efficient communication between the blood donors and blood centers.

The authors in (Prathamesh Raut et al. 2016) presented a web application that helps the blood bank administrator to meet the demand for blood supply. Similarly, it ensures that the request for blood is efficiently and effectively handled. The research was motivated by the need to bridge the gap between Recipient, Donor and Blood banks. The application (Made up of both Web and Mobile app) provides a platform for the stakeholders in the blood supply chain to check the availability of blood from the list of blood groups and ensure that request is not sent to the blood bank which is deficient of the required blood.

Sindhuja S. et al, (2016) proposed a blood donation service; the system could assist in the management of blood donor records with ease. The proposed system consists of two major components: 1) A Mobile phone with android operating system where the android app is installed. 2) A Server (usually a pc) for the website and the database where the information are stored. The Blood donor app notifies the latest news or information about blood donation camp details. It provides authenticated and authorized features to the current system where private and confidential data can only be viewed by authorized user.

Adarsh N et al(2014) proposed a RFID Blood management system to improve the safety of blood transfusions by using RFID tags that are placed directly on blood bags. The system can monitor the inventory status of the blood bank in real time and present more efficient and correct blood transfusions. Similarly, the system could produce different reports that medical personnel can make use of. The proposed system reduces the number of transfusion errors considerably by automating the entire process and performing crosschecks at various checkpoints. The inventory tracking provides real time status of the stock in the blood bank. Do-Sung Kim et al, (2007) proposed a system based on the RFID and ubiquitous sensor network. The proposed system provides a platform for error-free blood transfusion process. The system continuously reports the temperature of the Blood Bank's refrigerator and also tracks the location of a blood bag. The Location Tracking System (LTS) component of the system provides a useful way to track the movement of blood bags in designated time to provide accurate blood transfusions. Consequently, the automatic system for transporting blood bags will help to reduce both the time and effort of medical staff. This system makes managing blood bags simple and reliable.

\section{MATERIALS AND METHODS}

The newly designed system is both a web and mobile-based software system. The management of the various blood banks and hospitals are handled by the web component of the software. The administrator updates and modifies the details of various inventory of their respective blood banks would be restricted to the admin of the various blood bank registered on the platform. The android app allows the prospective donors to locate the available blood banks and also help blood recipient to match a donor.

\section{SYSTEM ANALYSIS AND DESIGN}

The systems development life cycle (SDLC) refers process of understanding how an information system (IS) can support business needs by designing a system, building it, and delivering it to users(Dennis Allan,2015). Information gathering is the first stage in the design of the mobile blood donation inventory system. Data obtained include the donor's details, blood types and information about the blood banks. The existing manual operation was represented using flowcharts and Use case diagrams as shown in figure 1 and figure 2 respectively. This gives better insights into the program flow during the system development stage. The User-friendly Interface was designed using HTML/CSS. Ionic, an hybrid mobile framework was adopted for the development of the mobile app. The web and the mobile components were integrated together for easy communication. Furthermore, the various software modules were integrated into a single software unit for deployment. Unit and user acceptability testing were carried out to ascertain the correctness of the system's output and the various methods in the code. 
International Journal of Engineering Applied Sciences and Technology, 2020

Vol. 5, Issue 4, ISSN No. 2455-2143, Pages 663-673

Published Online August 2020 in IJEAST (http://www.ijeast.com)

DONOR

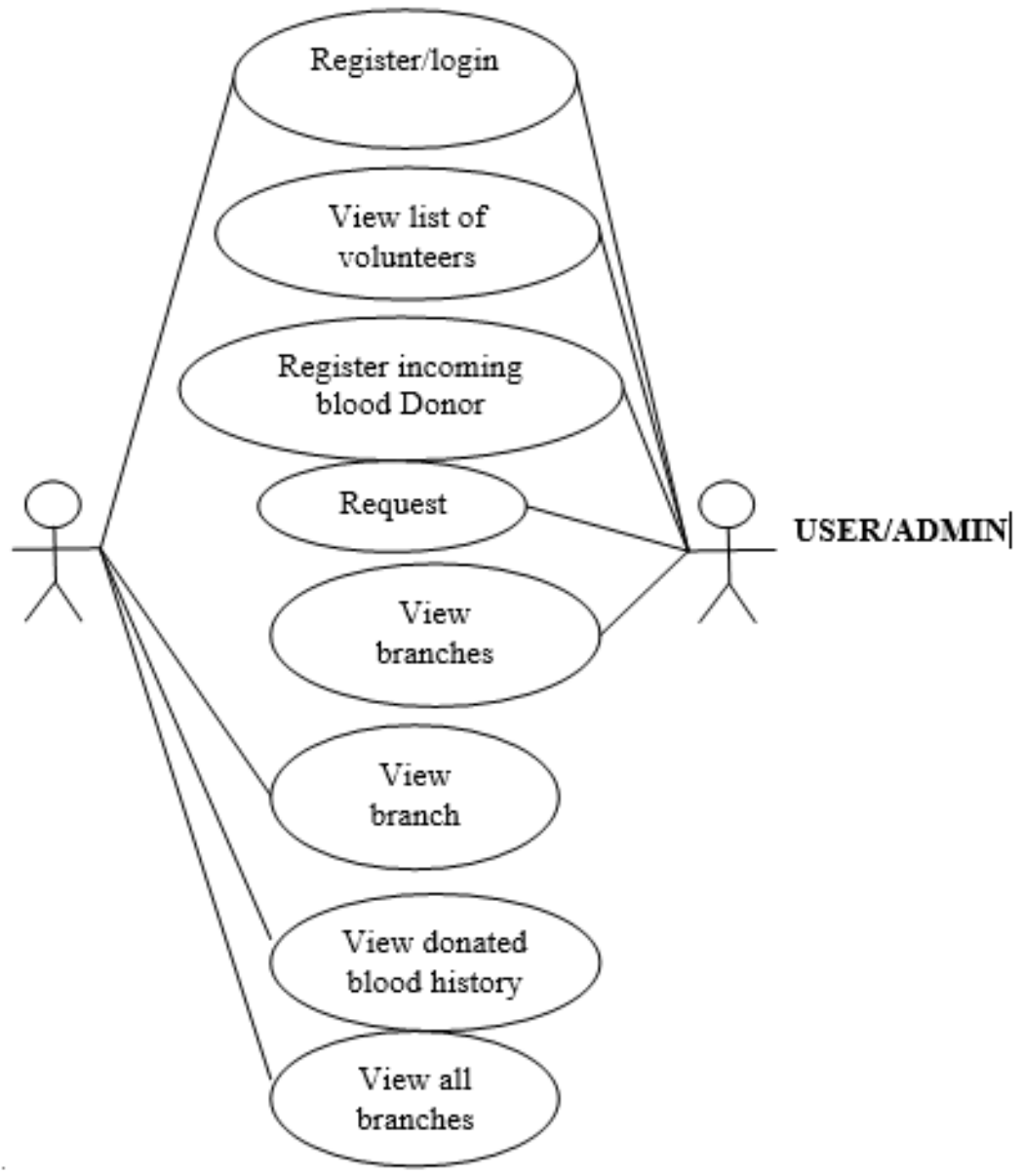

Figure 2. Use case Diagram hospital and blood bank 
International Journal of Engineering Applied Sciences and Technology, 2020

Vol. 5, Issue 4, ISSN No. 2455-2143, Pages 663-673

Published Online August 2020 in IJEAST (http://www.ijeast.com)

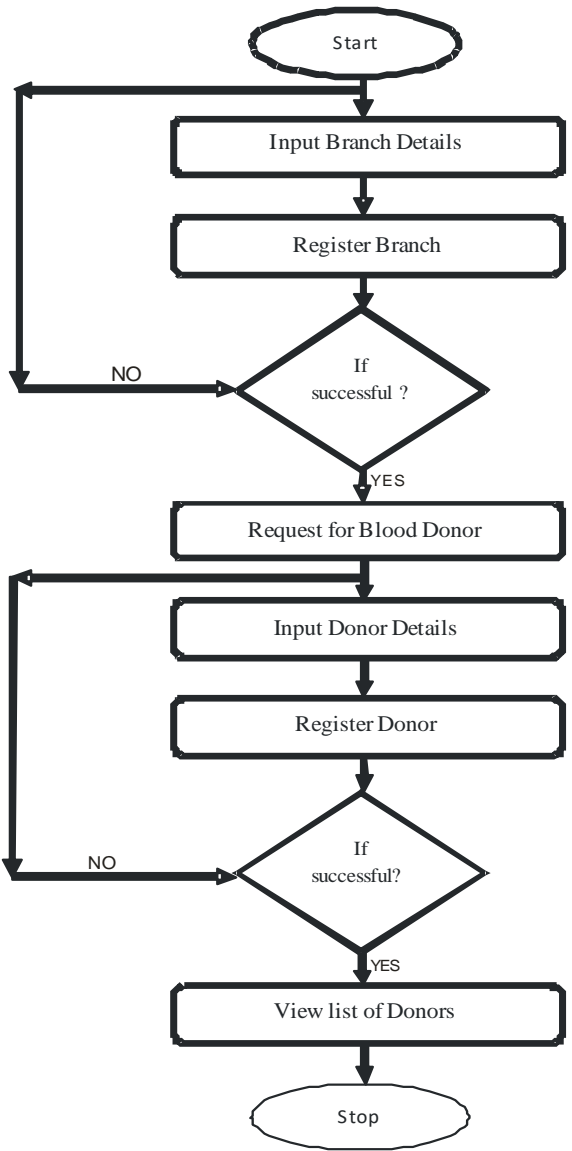

Figure 2. System's Flowchart

\section{SYSTEM IMPLEMENTATION AND STATISTICAL ANALYSIS}

\section{Software Implementation}

The snapshots in Figure 3 depicts the 'Login and Registration' module for the mobile app where the actual donors registered his/her details and also login to access the web blood donation app. Figure 4 is a module that shows the different blood types and blood bank branches where prospective donors can choose from. The module in figure 5 depicts the location of various blood banks on Google Map. The location of the blood banks was facilitated with the help of Google Map APIs.

The snapshot in figure 8 depicts the module for the login into the web components of the proposed Blood donation system. The admin provides a valid credentials or login detail before access is granted to modify or update information on the various blood banks. Figure 8 is a module that shows the administrator dashboard where the admin could access information on the volunteers, blood bank branches, blood donation among others.

\section{ANDROID PLATFORM}
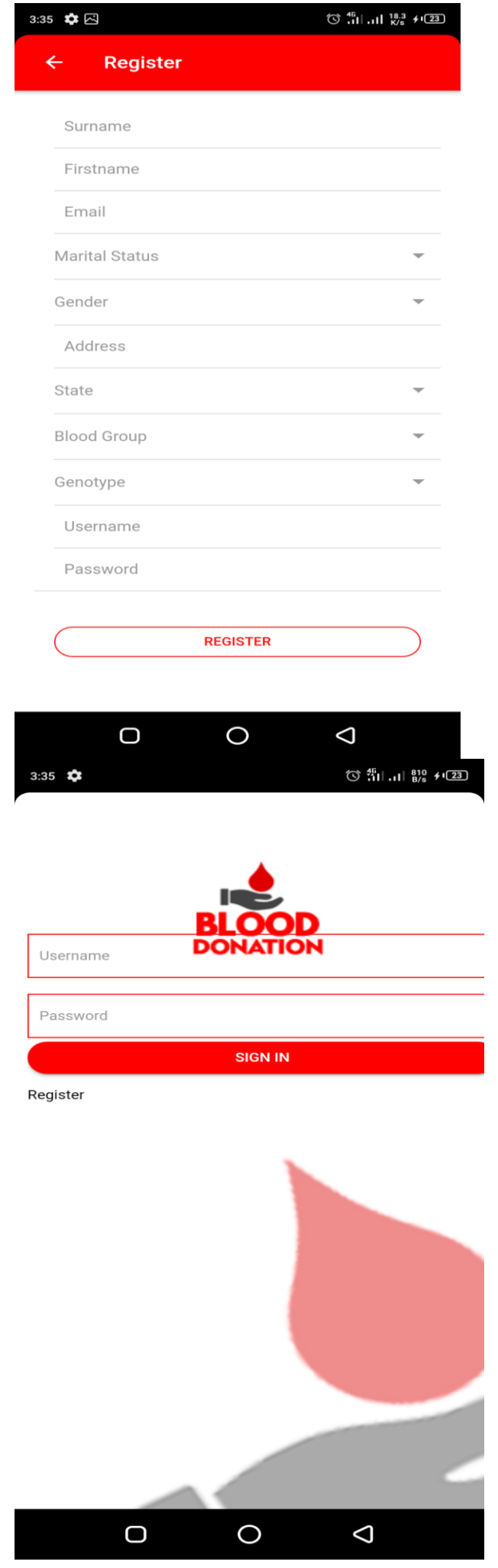

Fig 4: Donor Registration and Login page 
International Journal of Engineering Applied Sciences and Technology, 2020

Vol. 5, Issue 4, ISSN No. 2455-2143, Pages 663-673

Published Online August 2020 in IJEAST (http://www.ijeast.com)

Registration and Login page: Figure 3 is a module that accept donor registration and login details.

Donation Type Branch
$\begin{aligned} & \text { Blood } \\ & \text { The most Common Type of Donation.. }\end{aligned}$
$\begin{aligned} & \text { Power Red } \\ & \text { Best if you are O or Rh- negative.. }\end{aligned}$
$\begin{aligned} & \text { Platelets } \\ & \text { Donor must be AB Blood Type.. }\end{aligned}$
$\begin{aligned} & \text { AB Plasma } \\ & \text { Donot must be AB Blood Type.. }\end{aligned}$

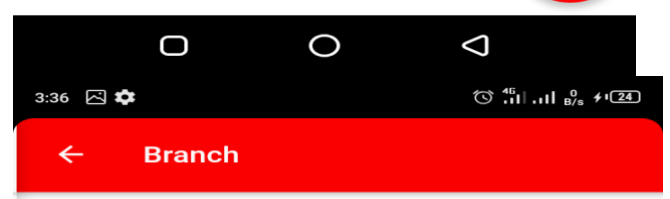

Lagos Red Cross Lagos,Ikeja Lagos.

- Abeokuta Ogun,3. temidire street, . wants to donate Similarly, The interface in Figure $4 \mathrm{~b}$ shows the list of blood donation camp branches .

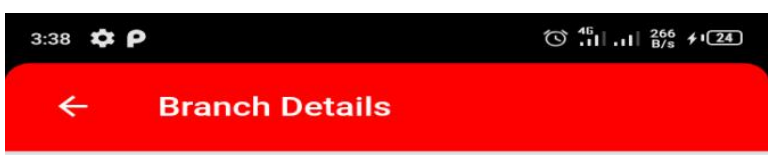

Lagos Red Cross

\section{Ikeja Lagos}

lagos@gmail.com

0818292929

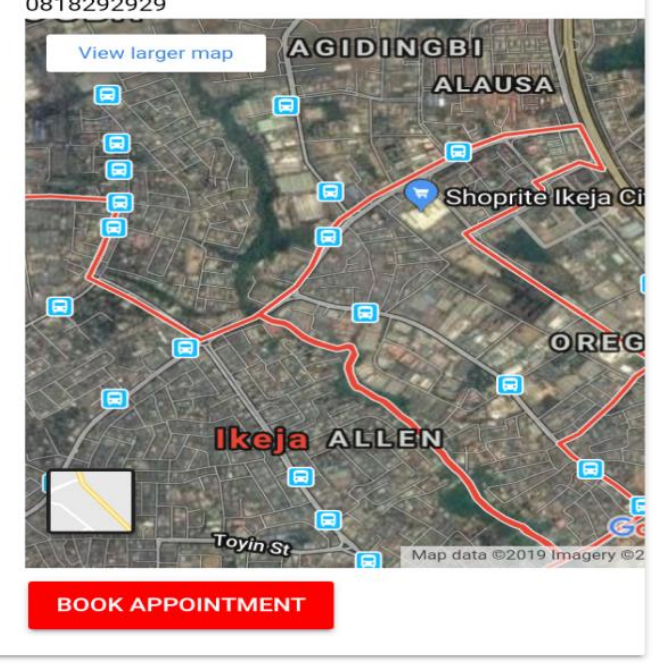

\section{○}

$\bigcirc$

$\triangleleft$

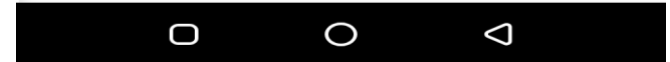

Fig 5: Blood Donation Type and Available Blood Bank Branch Page

The snapahots in Figure 4 depicts the blood donation type, where donor selects the type of blood he/she 
International Journal of Engineering Applied Sciences and Technology, 2020

Vol. 5, Issue 4, ISSN No. 2455-2143, Pages 663-673

Published Online August 2020 in IJEAST (http://www.ijeast.com)
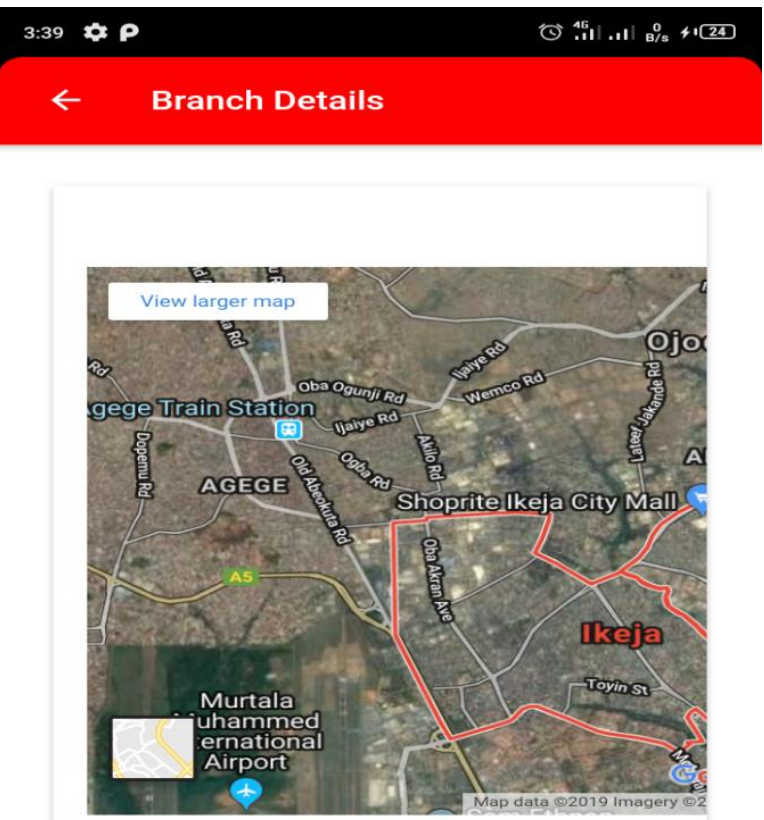

Appointment has been booked!

BOOK APPOINTMENT

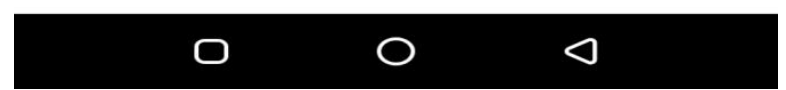

Fig 6:Location of Blood Bank Branch on Google Map

Branch Google Map: The interface above Fig 5 shows the map and route to the blood donation centers where donors can book appointment with a blood camp.

\section{WEB-BASED PLATFORM}

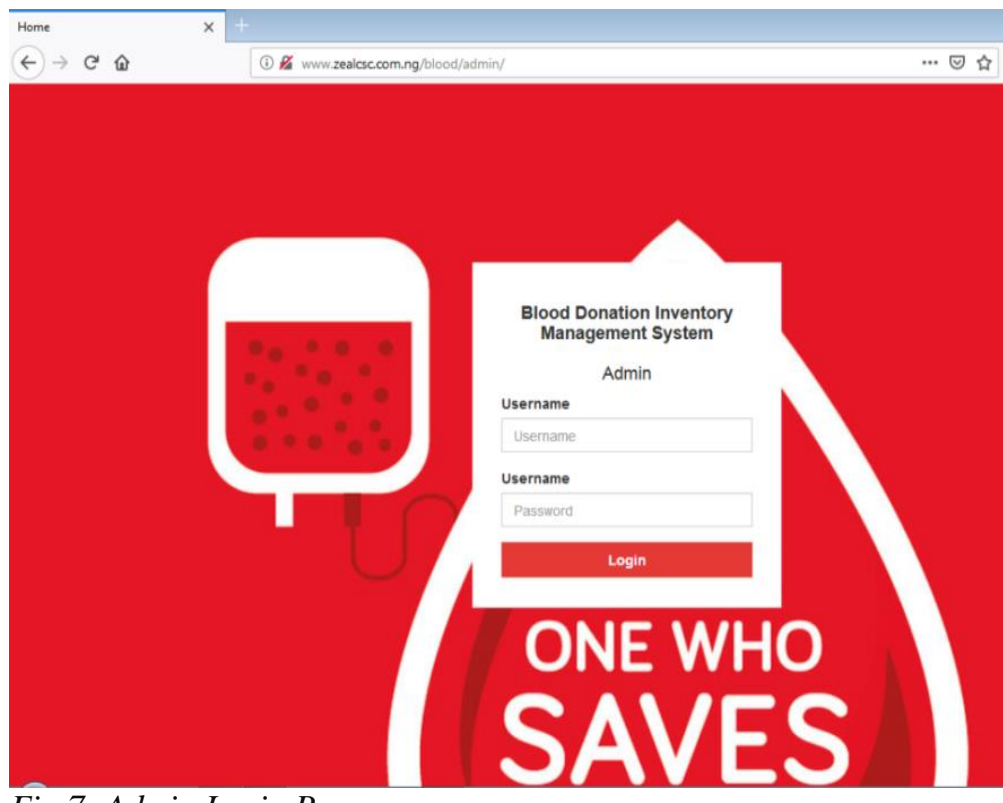

Fig 7: Admin Login Page

Admin Login Page: The module above provides a login page for the system administrator. The admin provides a valid login credentials before access is granted into the System.

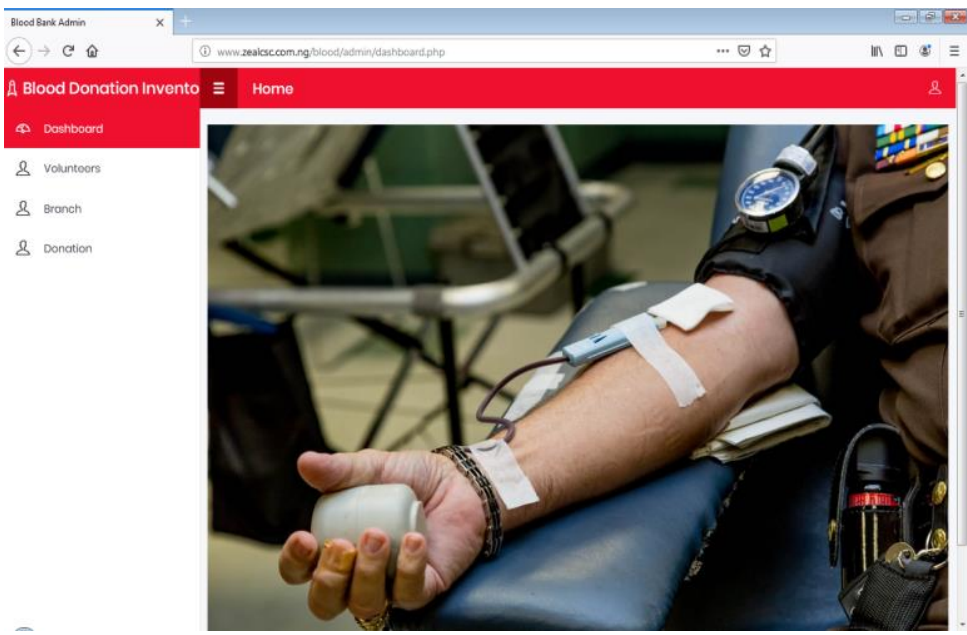

Fig 8: Administrator Dashboard

Administrator Dashboard: The fig 8 shows the Administrator dashboard. The perform operations from this page by clicking on the menu. 
International Journal of Engineering Applied Sciences and Technology, 2020

Vol. 5, Issue 4, ISSN No. 2455-2143, Pages 663-673

Published Online August 2020 in IJEAST (http://www.ijeast.com)

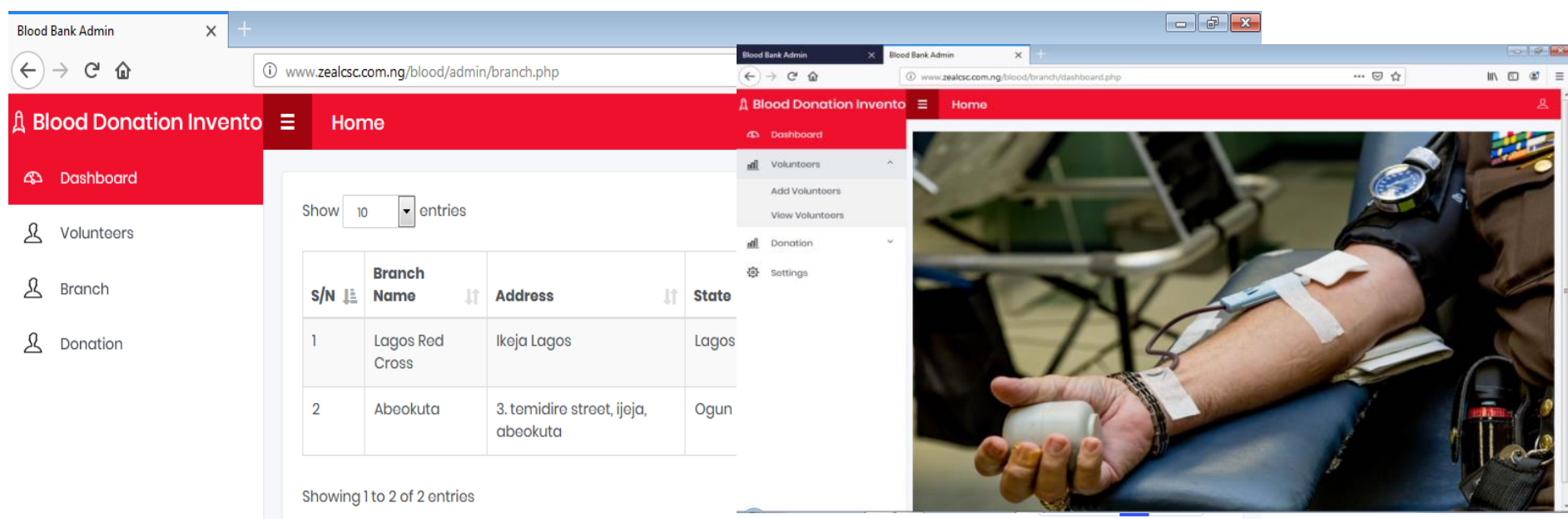

Fig 11: Branch Dashboard

Branch account: The picture above Fig 11 shows the Dashboard of user account, from this point, branch staff can perform various operations by clicking on the menu at the left side of the page.

\section{Fig 9: Branch List}

Branch List: The picture Fig 9 showcase the list of branches, from this point, admin can perform various operations on it.
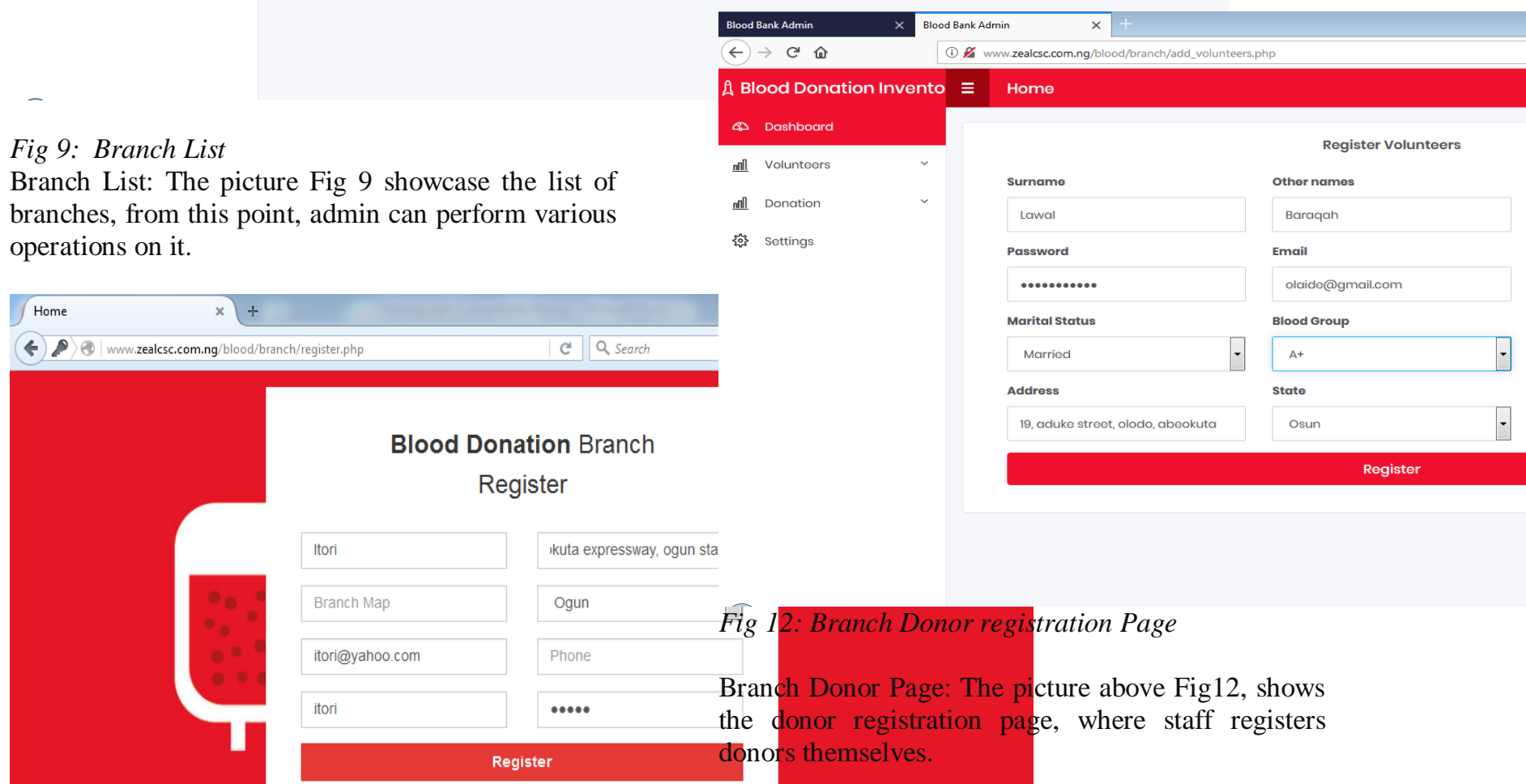

Already have a branch? Click here to login

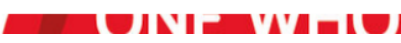

Fig 12: Branch Donor registration Page

Branch Donor Page: The picture above Fig12, shows the donor registration page, where staff registers donors themselves.

Fig 10 :Branch Registration Page

Branch Registration: The picture above Fig10 shows the branch registration page. The branch is required to provide all necessary details 
International Journal of Engineering Applied Sciences and Technology, 2020

Vol. 5, Issue 4, ISSN No. 2455-2143, Pages 663-673

Published Online August 2020 in IJEAST (http://www.ijeast.com)

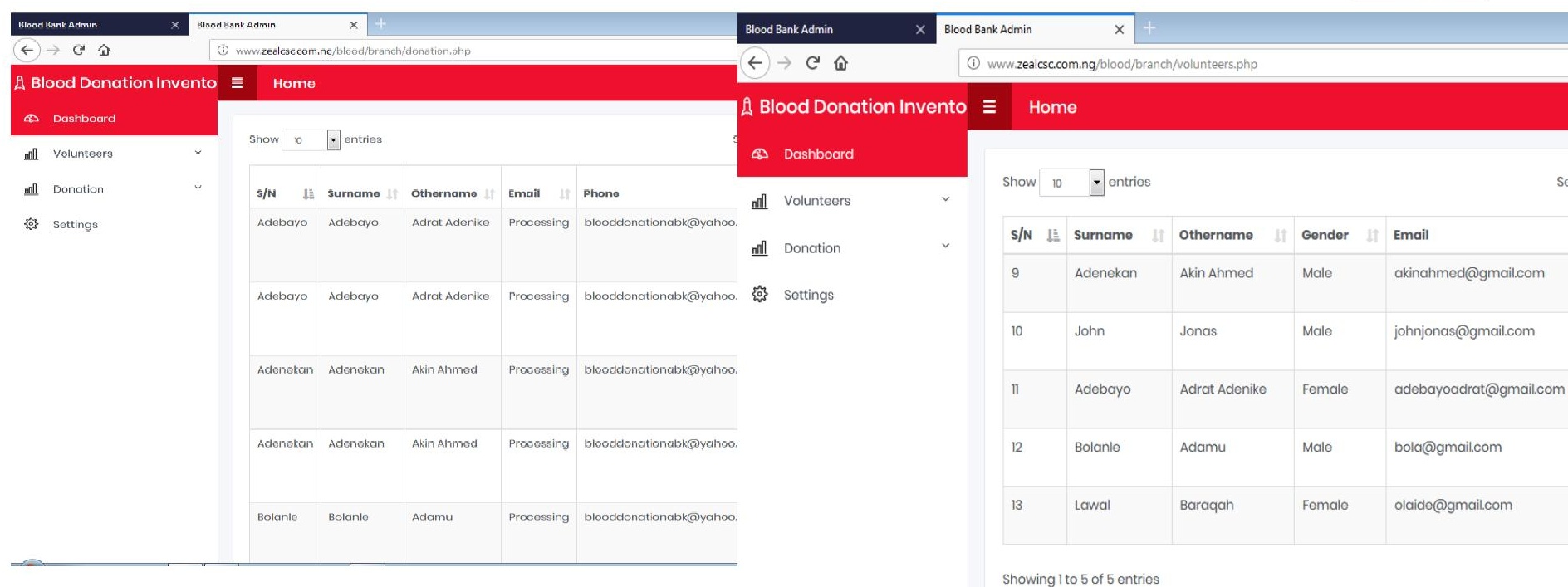

Fig 13: Donor Blood Donation Stages

Donor Blood Donation Stages: The picture above fig13 showcases the list of donor stages during blood donation process.

Fig 14: Volunteer List

Volunteer List: The picture above fig 14 showcase the list of donors registered to the branches for blood donation activities.

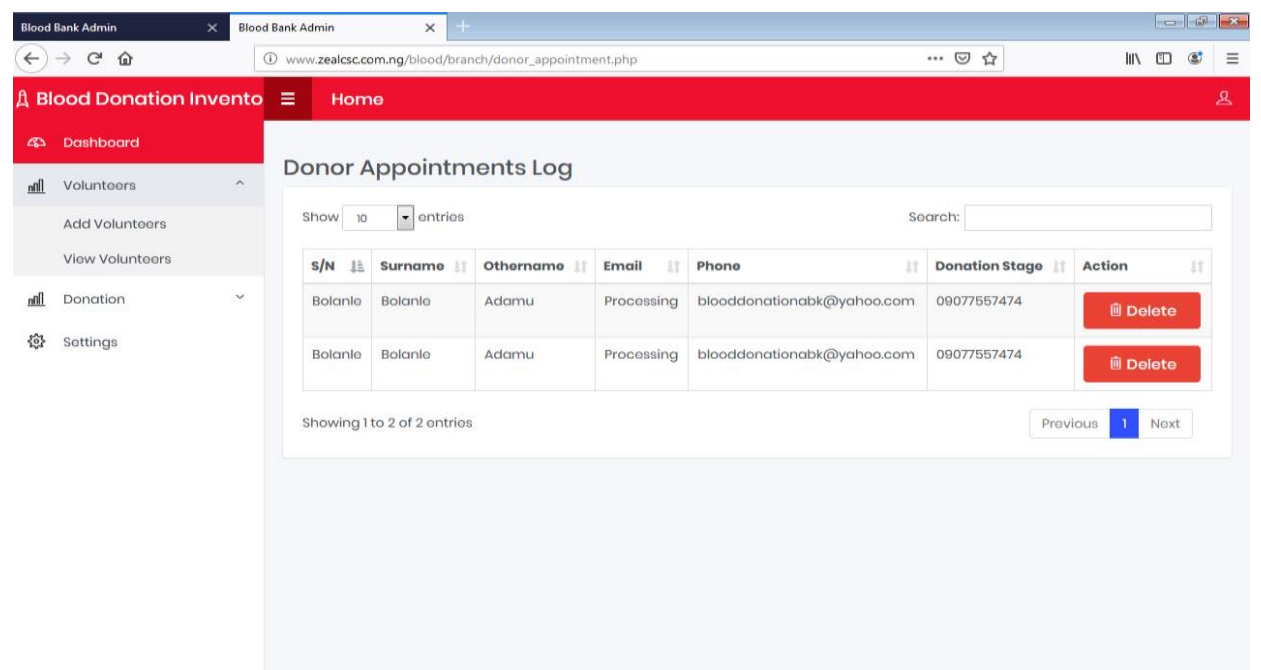

Fig 15: Donor Appointment Log

Donor appointment Log: The picture above in fig15 depicts the list of donor appointments made at the branches for blood donation process.

\section{USABILITY TESTING}

Usability testing was carried out to test if the application is easy, user friendly and efficient by prospective donors. A questionnaire was administered to fifty (50) users after installing the app and demonstrating the procedures to various donors. The respondents were selected randomly from four different locations across Ogun State; that is, Yewa, Abeokuta, Ijebu and Remo axes. The result obtained from the questionnaires is shown in table 1 below. 
Table 1: Summary of the responses of the respondents on the

\begin{tabular}{|c|c|c|c|c|c|}
\hline $\mathbf{S} / \mathbf{N}$ & Statement & $\mathbf{S A}$ & $\mathbf{A}$ & D & SD \\
\hline 1. & $\begin{array}{l}\text { Is the mobile app } \\
\text { easy to use? }\end{array}$ & $\begin{array}{c}25 \\
(50 \%)\end{array}$ & $\begin{array}{c}15 \\
(30 \%)\end{array}$ & $\begin{array}{c}8 \\
(16 \%)\end{array}$ & $\begin{array}{c}2 \\
(4 \%)\end{array}$ \\
\hline 2. & $\begin{array}{l}\text { Does the mobile } \\
\text { app loads faster? }\end{array}$ & $\begin{array}{c}36 \\
(72 \%)\end{array}$ & $\begin{array}{c}12 \\
(24 \%)\end{array}$ & $\begin{array}{c}1 \\
(2 \%)\end{array}$ & $\begin{array}{c}1 \\
(2 \%)\end{array}$ \\
\hline 3. & $\begin{array}{l}\text { Are the } \\
\text { Navigation, login } \\
\text { and other forms } \\
\text { easy to use? }\end{array}$ & $\begin{array}{c}23 \\
(46 \%)\end{array}$ & $\begin{array}{c}19 \\
(38 \%)\end{array}$ & $\begin{array}{c}5 \\
(10 \%)\end{array}$ & $\begin{array}{c}3 \\
(6 \%)\end{array}$ \\
\hline 4. & $\begin{array}{l}\text { Is the notification } \\
\text { feature for the } \\
\text { nearest blood } \\
\text { banks easy to } \\
\text { locate on the app }\end{array}$ & $\begin{array}{c}33 \\
(66 \%)\end{array}$ & $\begin{array}{c}16 \\
(32 \%)\end{array}$ & $\begin{array}{c}1 \\
(2 \%)\end{array}$ & - \\
\hline 5. & $\begin{array}{c}\text { Is the registration } \\
\text { module on the app } \\
\text { easy to use? }\end{array}$ & $\begin{array}{c}43 \\
(86 \%)\end{array}$ & $\begin{array}{c}5 \\
(10 \%)\end{array}$ & $\begin{array}{c}1 \\
(2 \%)\end{array}$ & $\begin{array}{c}1 \\
(2 \%)\end{array}$ \\
\hline 6. & $\begin{array}{l}\text { Is blood donation } \\
\text { easy to carry out } \\
\text { on the app? }\end{array}$ & $\begin{array}{c}33 \\
(66 \%)\end{array}$ & $\begin{array}{c}14 \\
(28 \%)\end{array}$ & $\begin{array}{c}6 \\
(12 \%)\end{array}$ & $\begin{array}{c}1 \\
(2 \%)\end{array}$ \\
\hline 7. & $\begin{array}{l}\text { Is the searching } \\
\text { and viewing of } \\
\text { various blood } \\
\text { banks easy on the } \\
\text { mobile app? }\end{array}$ & $\begin{array}{c}22 \\
(44 \%)\end{array}$ & $\begin{array}{c}21 \\
(42 \%)\end{array}$ & $\begin{array}{c}4 \\
(8 \%)\end{array}$ & $\begin{array}{c}3 \\
(6 \%)\end{array}$ \\
\hline 8. & $\begin{array}{l}\text { Is it Easy to } \\
\text { connect donors } \\
\text { and recipients } \\
\text { makes blood } \\
\text { donation way } \\
\text { more proficient } \\
\text { using this app? }\end{array}$ & $\begin{array}{c}31 \\
(62 \%)\end{array}$ & $\begin{array}{c}11 \\
(22 \%)\end{array}$ & $\begin{array}{c}4 \\
(8 \%)\end{array}$ & $\begin{array}{c}4 \\
(8 \%)\end{array}$ \\
\hline 10. & $\begin{array}{l}\text { Does the mobile } \\
\text { app ensure } \\
\text { seamless blood } \\
\text { transfusion } \\
\text { process? }\end{array}$ & $\begin{array}{c}12 \\
(24 \%)\end{array}$ & $\begin{array}{c}33 \\
(66 \%)\end{array}$ & $\begin{array}{c}3 \\
(6 \%)\end{array}$ & $\begin{array}{c}2 \\
(4 \%)\end{array}$ \\
\hline 11. & $\begin{array}{l}\text { Does the android } \\
\text { app make } \\
\text { communication } \\
\text { faster? }\end{array}$ & $\begin{array}{c}42 \\
(84 \%)\end{array}$ & $\begin{array}{c}7 \\
(14 \%)\end{array}$ & $\begin{array}{c}1 \\
(2 \%)\end{array}$ & - \\
\hline
\end{tabular}

usability of the mobile app.

Source: Researcher's field survey, 2019.

SA-Strongly Agreed, A-Agreed, D-Disagreed and SD means strongly disagreed

The table above (table 1) shows the responses of the respondents on each question as contained in the questionnaire used for the survey research. It was indicated that, 25(50\%) of the respondents strongly agreed with the statement that the mobile app is easy to use and $15(30 \%)$ of the respondents agreed with the statement, while the remaining respondents were either disagreed or strongly disagreed with the statement. In addition, $36(72 \%)$ of the respondents strongly agreed with the statement that the mobile app loads faster and 12(24\%) agreed with the question that the app loads faster. Furthermore, 23(46\%) and 19(38\%) of the respondents strongly agreed and agreed with the statement that the navigation, login and other forms are easy to use. 33(66\%) of the respondents strongly agreed with the statement that the notification feature for the nearest blood banks are easy to locate and $16(32 \%)$ of the respondents agreed with the statement. Moreover, 43(86\%) and 5(10\%) of the respondents strongly agreed and agreed with the statement that the registration module on the app are easy to use. 22(44\%) of the respondents strongly believed that the searching and viewing of various blood banks are easy on the mobile app and $21(42 \%)$ of the respondents agreed with the statement. On the connection of the donors and the recipients; $31(62 \%)$ of the respondents strongly agreed with the statement and $22 \%$ of the respondents agreed with the statement. On whether the mobile app ensure seamless blood transfusion process; $12(24 \%)$ of the respondents strongly agreed with the statement and $33(66 \%)$ of the respondents agreed with the statement, which is an indication that majority of the respondents are in favour of the question. Lastly, 42(84\%) of the respondents strongly agreed that the android app make communication faster and $7(14 \%)$ agreed with the statement.

\section{CONCLUSION}

This paper has presented the development of a web and mobile app for blood donation Inventory Management system. The automated system will simplify the manual blood donation process, reduce blood wastage and minimize blood transfusion errors. Furthermore, based on the statistical analysis of this research, Android-based Blood donation inventory system will provide a seamless and faster method of blood transfusion as evidenced by the opinion of the respondents. This study therefore recommends the full deployment of this prototype and its implementation which will ease the burden of the manual process of blood donation inventory system and improve blood transfusion activities in our various hospitals.

\section{REFERENCES}

[1]. Abu N. S. S., Ihab Z., Rreham K. A. (2016). Design and Development of Mobile Blood Donor Tracker. Journal of Multidisciplinary Engineering Science Studies (JMESS) ISSN: 2912-1309 Vol. 2 Issue 2, February

[2] Aishwarya S., Advait G., Varad S., Rajendra C. (2018). RedDonate: A Blood Bank Android Application. International, Journal of Recent Trends in Engineering \& Research (IJRTER) Volume 04, Issue 04. 
[3].Adarsh N, Arpitha J, Md. Danish Ali, Mahesh C. N., Pramodini G. M. (2014). Effective Blood Bank Management Based On RFID in Real Time Systems, International Conference on Embedded Systems - (ICES 2014

[4].Akora B. M, Mutonerwa S. m. ,kikomeko M., Nsimbi I F. (2018).Blood Donate Android Mobile Application. A Project Report Submitted to the School of Computing and Informatics Technology for the Study Leading to The Award of the Degree of Bachelor of Science in Computer Science.

[5]. Dennis Alan, Barbara Haley Wixom, David Tegarden. (2015). Systems analysis \& design: an object-oriented approach with UML. John Wiley \& sons. Fifth edition.

[6]. Do-Sung K, Sun K. Y., Kim H.O., Chang B.C., Bae H.S., Kim S.J. (2007). Location Based Blood Bag Management using active RFID and Ubiquitous Sensor Network . $6^{\text {th }}$ International Special Topic Conference on ITAB, Tokyo

[7]. Giridhar M., Narayan C. D., Soumya S. (2018). Data Warehouse Based Analysis with Integrated Blood Donation Management System.16th International Conference on Industrial Informatics (INDIN 2018), Porto, Portugal.

[8].Kayode A. A., Abidemi E. A., Roseline O. O. and Simon A. O. (2019). An Android based blood bank information Retrieval system.Journal of Blood Medicine 2019:10 119-125

[9]. Monika M., Pradnya J., Prachi M., Sonali Vidhate S. S. Patil.(2018). Implementation of Blood Donation Application using Android Smartphone .Open Access International of Science and Engineeering. Volume 3 Special Issue 1.

[10].Prathamesh R., Prachi P., Yogesh S., Sumeet N., Sanjay P. (2016).Blood Bank Management System. International Journal of Advanced Computational Engineering and Networking, ISSN: 2320-2106, Volume-4, Issue-9.

[11].World Health Organization.(2010).WHO

LibraryCataloguing in Publication Data

Design Guidelines for Blood Centres.

[12].Sadia N. D. (2018). Blood Donation Application with Implementation of Machine Learning. B.Sc. Thesis. Department of Computer Science and Engineering.Brac University.

[13].Sindhuja1, A.P., Priyadharshini V., Gothainayagi S., Devika M., Arul B. (2016). A Donor - Mobile Application for Saving Human Life. Journals. International Journal of Software \& Hardware Research in Engineering ISSN-23474890 Volume 4 Issue I.

[14]. Riya Dandekar, Shweta Mane, Ronak
Shah.(2020).Computerized Blood Bank Management System Using Geofencing, CLIO An Annual Interdisciplinary Journal of History, Vol-6-Issue-3 April-2020

[15].Margaret Butler. (2011). Android: Changing the Mobile Landscape. Pervasive computing.IEEE CS,1536-1268. 